\title{
Human Resources for Health (HRH) and challenges in Nepal
}

\author{
Sherchand JB \\ Tribhuvan University Institute of Medicine, Research Department, Maharajgunj, Kathmandu Nepal
}

Human Resource for Health (HRH) is one of the very important building blocks of the health care system. The health resources include different categories of health professionals ranging from doctors, nurses, paramedics, mid-level health professionals of different specialty of health sciences, public health professionals and researchers. The community health workers and volunteers are also very important human resources for health. Provision of sufficient number of different types and categories of Human Health Resources and their proper utilization in health work environment is a pre-requisite for better functioning of health care system ${ }^{1}$.

In Nepal, Human Resources for Health (HRH) situation have been met with several key challenges particularly related to the shortage and uneven distribution of the health workforce in the country ${ }^{2}$. Despite the need for an appropriate number and distribution of different categories or level of health personnel, who are socially responsible, technically competent and are available at the right time and place $^{3}$, as outlined in the National Health Policy 1991, these challenges have prevented policy from being translated into practice. Moreover, the National Health Policy has not taken into consideration the epidemiological transitions and demographic developments that have occurred over the last two decades.

Although South-East Asia is one of the endemic zones to approximately 25 percent of the world's population with almost 30 percent of the global disease burden, it has only 10 percent of the global health workforce ${ }^{4}$. Nepal reflects the regional context, and has been identified by the World Health Organization as one of 57 nations with a critical shortage of health workers ${ }^{5}$. This creates a huge deficit in the requirements for high coverage of essential interventions, including those necessary to meet the healthrelated Millennium Development Goals (MDGs). In Nepal, this is unlikely until the threshold density of health workers (doctors, nurses and midwives) is at least 23 per 10,000 in the population ${ }^{6}$. Furthermore, policy has not addressed the changing demographics in the country, as despite a population increase of more than 45 percent in the last two decades the human health resources has increased by
3.4 percent during that time ${ }^{7}$. The distribution of health workers has been raised as a concern in Nepal, with huge variations between ecological zones (Mountain, Hill and Tarai) and among the ${ }^{5}$ development regions of the country (Far-Western, Mid-Western, Western, Central and Eastern). The absence of doctors and qualified health professionals in the most remote areas has also been a long standing issue. These issues are compounded by the movement of high-level health workers, such as doctors and nurses, to private health institutions or overseas, due to the high demand for health workers in industrialized countries, as well as attractive incentives that they offer.

In Nepal, prevention and control of infectious diseases remains fragile agenda whereas the emergence of noninfectious on the other hand represents more than half the burden of diseases due to a changing lifestyle and environment. Current triple burden diseases as well as mixed epidemiological transition and new emerging diseases, require more public health expert, epidemiologists and concern health researchers to intervene any health problem at the population level.

The most recent draft of the Human Resources for Health Strategic Plan 2011-2015 has identified major challenges related to $\mathrm{HRH}$ in the country. These include imbalances in the mix of staff and skills, particularly in light of the changing burden of disease, changing healthcare technologies and increasing population and demand for quality curative services. National policies and plans have not been based on detailed evidence regarding the situation on ground ${ }^{7}$.

Dussault and Franceshini have mentioned in their review article that there is an abundance of HRH production, especially doctors and nurses, in Nepal therefore like in other developing countries; the "brain drain" of health workers has been identified as a major concern ${ }^{8}$. Previous research has identified that professional Councils are being approached for letters of good standing by staff wanting to work abroad and data suggests approximately $16 \%$ of registered doctors are outside the country studying or working ${ }^{9,10}$. The uneven distribution of health workers has been a major concern in the health sector and the 
deployment of health personnel to the rural and remote areas of the country is a challenge. Although, Nepal produces an adequate number of doctors and nurses there are still huge shortage of qualified midwives. A total of national stock of 8,771 medical doctors, only 1,062 are working in sanctioned government posts and about 300 are working in government posts under the Ministry's scholarship programme. Two thirds of health staffs are working in either the Kathmandu Valley or in other cities, leaving rural areas under-staffed, with absenteeism a growing problem $^{6,7}$.

In Nepal, health sector constitutes about one-fourth of total personnel of the public sector. The existing data revealed that only $4 \%$ of total health care providers are doctors, $12 \%$ nurses, excluding ANMs, $47 \%$ paramedics, $0.92 \%$ public health officers, and $3.1 \%$ traditional health care providers. Still there is high number of unskilled support staff $(28 \%$ of the total health care workers). This poses a challenge to the health system to reduce the volume of unskilled and semi-skilled labor as a percentage of the total health care workers ${ }^{11}$.

The main issues in the human resource for health of Nepal are retention, inadequate skill manpower, improper distribution, inadequate finance, low opportunity for pre and in-service training. Current recognition of these issues by the government of Nepal, developed the Human Resource for Health Strategy in 2003 for 14 years, i.e. 2003 -2017 . However, this could not become effective because of inadequate projection, poor implementation, inadequate funding, and ownership by the stakeholders. Therefore new initiative plan has been developed in 2010 a comprehensive HRH Strategic (2011-2015) to address long standing problem of human resources in the health sector ${ }^{12}$.

In addition, the notable feature in human resource for health development in the Nepal is that the private sector has emerged as a substantial force in HRH and can contribute service delivery in coordination with public sectors; however the coordination between these two sectors are very weak. So, government should have strong policy and coordinated bodies and public private partnership should be strengthened.

\section{References}

1. Ministry of Health and Population (MoHP) [Nepal]. Human Resources for Health Strategic Plan 20112015. Kathmandu: Ministry of Health and Population, Government of Nepal 2012.

2. Human Resource Information Center, Ministry of Health and Population, Report, 2008
3. Government of Nepal. National Health Policy 1991. Ministry of Health, Government of Nepal; 1991.

4. WHO SEARO. Health Systems Development- Human Resources for Health. [Electronic] 2008 [updated June18, 2008; cited 2012 February 16]; Available from: http://www.who.int.

5. World Health Organization. WHO Global Atlas of the Health workforce. Available from: htpphttp://www. who.int/globalatlas.

6. Ministry of Health and Population (MoHP) [Nepal]. Nepal Health Sector Programme II (NHSP- II) 20102015 Kathmandu: Ministry of Health and Population, Government of Nepal 2010.

7. Ministry of Health and Population (MoHP) [Nepal]. Nepal Health Sector Programme Implementation Plan II (NHSP-IP II) 2010-2015 Final Draft. Kathmandu: Ministry of Health and Population, Government of Nepal 2010.

8. Dussault G, Franceschini MC: "Not enough there, too many here: understanding geographical imbalances in the distribution of the health workforce" Human Resource for Health 2006; 4: 12-20

9. Blair George, Human Resource Information System Assessment Report: Nepal Ministry of Health and Population and NHSSP II, Strengthening Health System-Improving Services 2011.

10. Dixit H: Training of doctors in Nepal. [http://www. moph.go.th/ops/hrdj/] 1998; Journal of Human Resources for Health Development.

11, Blair George, Human Resource Information System Assessment Report: Nepal Ministry of Health and Population and NHSSP II, Strengthening Health System-Improving Services 2011.

12. Shrestha C, Bhandari R. Insight into Human Resources for Health Status in Nepal, Health Prospect 2012; $11: 40-41$ 